\title{
Analysis and Control of Modular Multilevel Converters under Asymmetric Arm Impedance Conditions
}

\author{
Rong Zeng, Student Member, IEEE, Lie Xu, Senior Member, IEEE, Liangzhong Yao, Senior \\ Member, IEEE, and Stephen J. Finney
}

\begin{abstract}
This paper presents a detailed analysis and improved control strategy for Modular Multilevel Converters (MMC) under asymmetric arm inductance conditions. Unlike symmetric conditions, the fundamental ac current is not split equally between the upper and lower arms under asymmetric conditions, and the dc and double-frequency components in the common-mode current also flow into the ac side. To solve these issues, a theoretical analysis of the effect of asymmetric conditions on MMC operation is carried out using equivalent circuits at different frequencies. Three control targets are then presented to enhance the operational performance. A control strategy providing the control of differential-mode current, common-mode current and power balance is designed. The feasibility and validity of the proposed analysis and control strategy are demonstrated by simulation results from a threephase MMC system, and simulation and experimental results from a single-phase MMC system.
\end{abstract}

Index Terms--Modular multilevel converter, differential-mode current, common-mode current, power balance, asymmetric conditions.

\section{INTRODUCTION}

$\mathrm{T}$ HE modular multilevel converter (MMC) has drawn attention due to its advantages of modular design, high efficiency and scalability, and excellent output waveforms with low harmonic distortion [1-10].

Due to the MMC's unique configuration, there are complex interactions involving different currents and voltages in the MMC, and extensive research has been conducted on the modeling and control strategy of the MMC [11-22]. The relationship between the arm current and capacitor voltage was analyzed in [11] and [12]. One of the special characteristics of the MMC is the common-mode current which usually includes a dc component and even-order (mainly the second-order) harmonic components. The common-mode current flows through the three-phase legs of

Manuscript received September 3, 2014; revised January 4, 2015, March 27, 2015 and June 26, 2015; accepted July 25, 2015.

Copyright (c) 2015 IEEE. Personal use of this material is permitted. However, permission to use this material for any other purposes must be obtained from the IEEE by sending a request to pubs-permissions@ieee.org.

R. Zeng, L. Xu, and S. Finney are with the Department of Electronic and Electrical Engineering, University of Strathclyde, Glasgow G1 1XW, UK. (email: $\quad$ rong.zeng@strath.ac.uk; lie.xu@strath.ac.uk, stephen.finney@strath.ac.uk )

L.Z. Yao is with China Electric Power Research Institute, Xiaoying Road, Beijing, 100192, China (email: yaoliangzhong@epri.sgcc.com.cn) the MMC, affecting the capacitor voltage in the sub-modules (SM) and the energy variation in each arm, but it does not affect the ac side current (differential-mode current). Many control strategies have been developed such as circulating current control [15-18] and energy-based modeling control [19-22]. The circulating current control method suppresses the even-order common-mode harmonic current by adding extra controllers, such as a proportional-integral (PI) controller in a double-frequency rotational frame [15], a series of resonant controllers tuned at even-order harmonic frequencies [16], or a repetitive controller [17-18]. The energy-based modeling control is based on the schemes of regulating the total energy and energy balancing [19-23]. Although extensive work on the modeling analysis and control of the MMC has been carried out, these analyses were based on symmetric conditions (i.e. balanced input voltages and symmetric arm impedances), assuming that the common-mode current mainly involves the even-order harmonic component and would not affect the differential-mode (output ac) and dc current. MMC operation under unbalanced input ac voltage conditions was analyzed in [24-27]. It revealed that under such unbalanced conditions, the common-mode current not only contains a dc component and even-order circulating harmonic components, but also includes a second-order zero-sequence harmonic component within the three converter legs, resulting in second-order harmonic components in the dc voltage and current. To eliminate the second-order harmonic oscillations on the de voltage and current, two methods were proposed: one suppresses the dc voltage ripple [24], and the other directly eliminates the zerosequence harmonic current [25-27]. In [27], the possible impact of MMC with asymmetric arm impendence was briefly mentioned and it revealed that the ac current would not split equally between the upper and lower arms, resulting in a fundamental-frequency common-mode current. However, the detailed system analysis and investigations of the influence of the common-mode current flowing into both ac and dc sides caused by asymmetric arm impedance have not been conducted, and the specific control requirement has not been considered.

In this paper, a detailed analysis on the asymmetrical MMC with asymmetric arm impedance is conducted, and a mathematical analysis of its negative influences on the ac and dc side electrical quantities is performed. Based on the developed mathematical model, three control targets are presented to eliminate the negative impacts caused by the asymmetric arm impedance and an improved control strategy focusing on these three control targets is proposed. 


\section{IEEE TRANSACTIONS ON INDUSTRIAL ELECTRONICS}

The paper is organized as follows. Section II introduces the basic MMC operation and Section III analyses MMC behavior with asymmetric arm impedance using different-frequency based sub-circuits. An improved control strategy for the asymmetric MMC is proposed in Section IV. Sections V and VI present the simulation results for a three-phase system and the simulation and experimental results for a single-phase system, respectively. Finally Section VII draws conclusions.

\section{BASIC MMC OPERATION}

The circuit configuration of a three-phase MMC is shown in Fig. 1. $V_{d c}$ is the dc-link voltage and $L$ is the arm inductor in each arm. $v_{a p}, v_{b p}, v_{c p}$ and $v_{a n}, v_{b n}, v_{c n}$ are the total voltages generated by all the SMs in the upper and lower arms, respectively. $i_{a p}, i_{b p}, i_{c p}$ and $i_{a n}, i_{b n}, i_{c n}$ are the currents in the upper and lower arms, respectively. $i_{a} i_{b}$ and $i_{c}$ are the output ac phase currents.

Fig. 1 Basic structure of a three-phase MMC

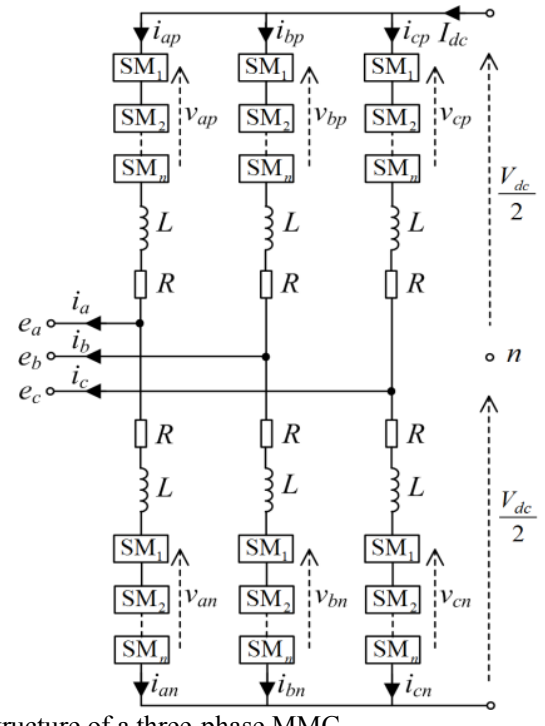

According to MMC operation principles, the arm current contains one differential-mode current $i_{j d m}$ and one commonmode current $i_{j c m}$ where the subscript $j$ refers the three-phase quantities of $a, b$, and $c$. During normal symmetrical conditions, that is, all six arm reactors are identical, the differential-mode current flows to the three-phase ac side and the common-mode current flows within the upper and lower arms having no effect on the ac side. The arm currents $i_{a p}$ and $i_{a n}$ can therefore be expressed as (taking phase $a$ as an example)

$$
\left\{\begin{array}{l}
i_{a p}=i_{a d m} / 2+i_{a c m} \\
i_{a n}=-i_{a d m} / 2+i_{a c m}
\end{array}\right.
$$

where $i_{a d m}$ and $i_{a c m}$ are [15]

$$
\left\{\begin{array}{l}
i_{a d m}=I_{m} \sin (\omega t-\phi) \\
i_{a c m}=I_{d c} / 3+I_{a c m 2} \sin \left(2 \omega t-\phi_{a c c 2}\right)
\end{array}\right.
$$

In (2), $I_{m}$ is the peak ac side current, $I_{a c m 2}$ is the peak of the double frequency component (higher order harmonic currents are neglected due to their small magnitudes) in the commonmode current, and $I_{d c}$ is the dc side current.
Taking the neutral point $n$ of the dc link as the voltage reference, the arm voltage can be expressed as

$$
\left\{\begin{array}{l}
v_{a p}=\frac{1}{2} V_{d c}-\left(R i_{a p}+L \frac{d i_{a p}}{d t}\right)-e_{a} \\
v_{a n}=\frac{1}{2} V_{d c}-\left(R i_{a n}+L \frac{d i_{a n}}{d t}\right)+e_{a}
\end{array}\right.
$$

Combining (1) and (3) yields,

$$
\left\{\begin{array}{l}
2 \times\left(R i_{a c m}+L \frac{d i_{a c m}}{d t}\right)=V_{d c}-\left(v_{a p}+v_{a n}\right)=u_{a c m} \\
\frac{1}{2}\left(R i_{a d m}+L \frac{d i_{a d m}}{d t}\right)=\frac{1}{2}\left(v_{a n}-v_{a p}\right)-e_{a}=u_{a}-e_{a}
\end{array}\right.
$$

where $u_{a}$ is the equivalent phase voltage in phase $a$ and can be used to regulate the differential-mode current. $u_{a c m}$ is the voltage difference between the dc side voltage and the total leg voltage, and can be used to control the common-mode current.

Based on (4), the upper and lower arm voltages are:

$$
\left\{\begin{array}{l}
v_{a p}=V_{d c} / 2-u_{a}-u_{a c m} / 2 \\
v_{a n}=V_{d c} / 2+u_{a}-u_{a c m} / 2
\end{array}\right.
$$

Thus, the instantaneous power flowing into the upper and the lower arms can be expressed as the product of the arm voltage in (5) and the arm current in (1):

$$
\left\{\begin{aligned}
p_{a p}=v_{a p} i_{a p} & =\left(1 / 4 V_{d c} i_{a d m}-1 / 4 u_{a c m} i_{a d m}-u_{a} i_{a c m}\right) \\
& \left(1 / 2 V_{d c} i_{a c m}-1 / 2 u_{a c m} i_{a c m}-1 / 2 u_{a} i_{a d m}\right) \\
p_{a n}=v_{a n} i_{a n} & =-\left(1 / 4 V_{d c} i_{a d m}-1 / 4 u_{a c m} i_{a d m}-u_{a} i_{a c m}\right) \\
& +\left(1 / 2 V_{d c} i_{a c m}-1 / 2 u_{a c m} i_{a c m}-1 / 2 u_{a} i_{a d m}\right)
\end{aligned}\right.
$$

\section{MODELING OF THE ASYMMETRICAL MMC}

Fig. 2 shows the equivalent circuit of an asymmetrical MMC, since in reality impedances in all the arms will not be equal. $\widetilde{v}_{a p}, \widetilde{v}_{b p}, \widetilde{v}_{c p}$ and $\tilde{v}_{a n}, \widetilde{v}_{b n}, \widetilde{v}_{c n}$ represent the ac components in the generated arm voltage which mainly contain fundamental and second order harmonic components whereas $\bar{v}_{a p}, \bar{v}_{b p}, \bar{v}_{c p}$ and $\bar{v}_{a n}, \bar{v}_{b n}, \bar{v}_{c n}$ denote the dc offsets in the arm voltage.

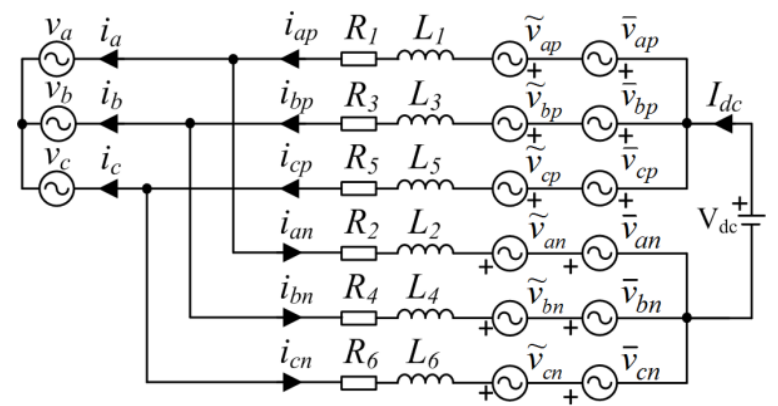

Fig. 2 Equivalent circuit of an asymmetrical MMC 
The linear circuit shown in Fig. 2 can be divided into three sub-circuits using the superposition principle, giving different frequency voltage sources, i.e. dc, fundamental frequency ac and double frequency ac sources.

\section{A. Fundamental frequency sub-circuit}

For conventional MMC control [12], the upper and lower fundamental frequency voltage sources within each phase are identical but with opposite signs. Fig. 3 presents the MMC equivalent circuit for the fundamental frequency quantities. $\widetilde{v}_{a 1}, \widetilde{v}_{b 1}$, and $\widetilde{v}_{c 1}$ denote the fundamental frequency voltage source in phase a, b, and c, respectively. Note the opposite directions for the voltages in the upper and lower arms in Fig. 3.

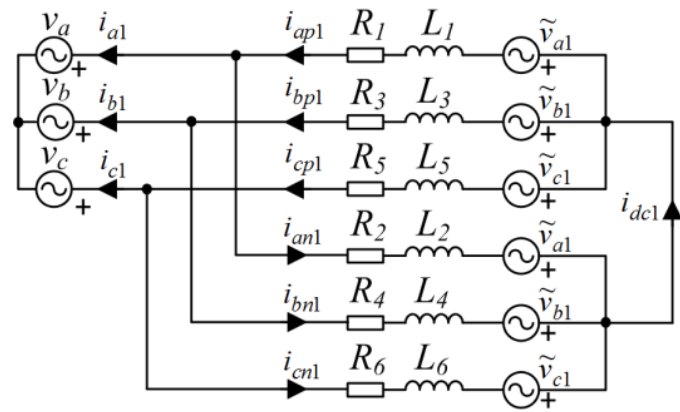

Fig. 3 Sub-circuit illustrating the fundamental frequency quantities.

The circuit in Fig. 3 can be analyzed in two steps. The first step uses Thevenin's equivalent circuit for representing the MMC to calculate the ac output current $i_{a l}, i_{b l}$, and $i_{c l}$. The simplified circuit is shown in Fig. 4 (a) where the arm resistances are neglected for ease of calculation, and

$$
\begin{aligned}
& L_{12}=L_{1} L_{2} /\left(L_{1}+L_{2}\right) \\
& L_{34}=L_{3} L_{4} /\left(L_{3}+L_{4}\right) \\
& L_{56}=L_{5} L_{6} /\left(L_{5}+L_{6}\right)
\end{aligned}
$$

The circuit in Fig. 4 (a) can be analyzed by considering the three-phase unbalanced inductances which results in unbalanced line currents $i_{a l}, i_{b l}$, and $i_{c l}$ [29].

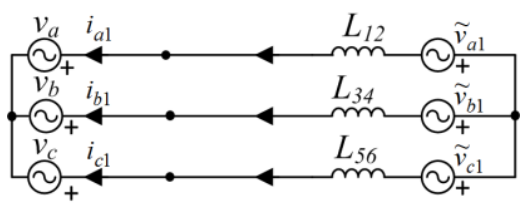

(a)

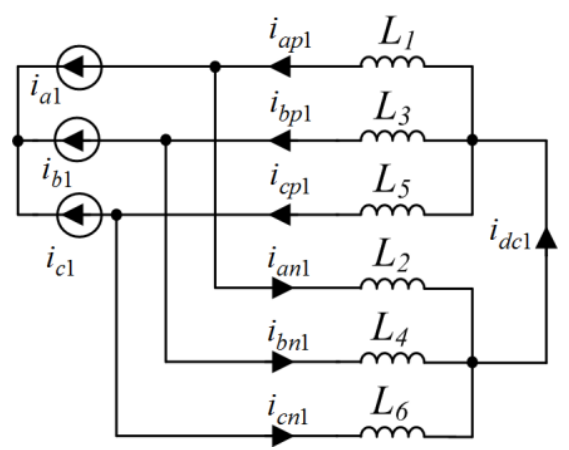

(b)

Fig. 4 Equivalent circuit at fundamental frequency for: (a) calculating ac current and (b) calculating arm and dc current.
Next the second step considers the output ac currents as three-phase current sources as in Fig. 4 (b). The steady-state arm current and the current flow through the dc side can then be calculated as

$$
\begin{array}{ll}
i_{a p 1}=\frac{L_{2}}{L_{1}+L_{2}} i_{a 1} & i_{a n 1}=\frac{-L_{1}}{L_{1}+L_{2}} i_{a 1} \\
i_{b p 1}=\frac{L_{4}}{L_{3}+L_{4}} i_{b 1} & i_{b n 1}=\frac{-L_{3}}{L_{3}+L_{4}} i_{b 1} \\
i_{c p 1}=\frac{L_{6}}{L_{5}+L_{6}} i_{c 1} & i_{c n 1}=\frac{-L_{5}}{L_{5}+L_{6}} i_{c 1} \\
i_{d c 1}=i_{a p 1}+i_{b p 1}+i_{c p 1} \neq 0
\end{array}
$$

Thus, asymmetrical inductances in the two arms in each phase result in different fundamental arm currents, i.e. unequal current sharing between the upper and lower arms. Additionally, there can also be fundamental current through the dc side which causes extra dc voltage and current ripples.

\section{B. Double frequency sub-circuit}

Based on the analysis in [12], the double frequency components in the common-mode current are generated by the common-mode ripple voltage source with the same orientation in the upper and lower arms. Fig. 5 shows the equivalent circuit for the double frequency quantities, where $\widetilde{v}_{a 2}, \widetilde{v}_{b 2}, \widetilde{v}_{c 2}$ denote the double frequency voltage sources. The circuit shown can be analyzed using the same approach as for the fundamental components shown in previous sections. When the arm impedances are symmetrical, the upper and lower arm currents for each phase are identical, e.g. $i_{a p 2}=i_{a n 2}$ for phase $a$. This leads to $i_{a 2}=0$ which means the second order harmonic current only appears as commonmode in the arms without affecting the ac output current. Under such a condition, the sum of the three-phase double frequency common-mode currents is also zero, thus such current components do not appear on the dc side, i.e. $i_{d c 2}=0$. Under asymmetrical conditions, however, the double frequency common-mode currents flowing through the upper and lower arms in each phase are not equal and their difference flows to the ac side $\left(i_{a 2} \neq 0, i_{b 2} \neq 0, i_{c 2} \neq 0\right)$. Meanwhile, the sum of the three-phase double frequency current is not zero, and will appear on the dc side, i.e. $i_{d c 2} \neq 0$.

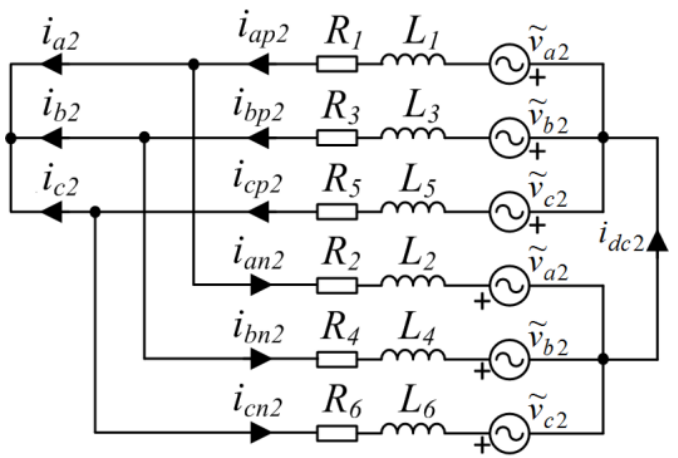

Fig. 5 Sub-circuit illustrating the double frequency quantities.

\section{DC sub-circuit}

Adopting the conventional control strategy, the dc offsets in the upper and lower arm are equal and have the same 
orientation. Fig. 6 shows the equivalent circuit for the dc quantities where $\bar{V}_{a}=\bar{V}_{b}=\bar{V}_{c}=V_{d c} / 2$. Under symmetrical conditions, the upper arm currents $\bar{i}_{a p}, \bar{i}_{b p}, \bar{i}_{c p}$ are identical to the lower arm currents $\bar{i}_{a n}, \bar{i}_{b n}, \bar{i}_{c n}$, and all equal $1 / 3 I_{d c}$. When the arm resistances differ, the dc currents in the upper and lower arms become unequal and consequently, a dc current component appears on the ac side, i.e. $\bar{i}_{a} \neq 0$ taking phase $a$ as an example.

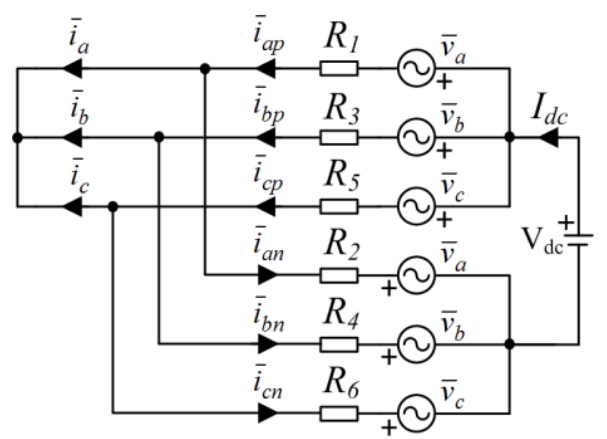

Fig. 6 Sub-circuit illustrating the de quantities.

\section{Power flow analysis}

According to the previous analysis, under asymmetrical conditions, the differential-mode and the common-mode currents in phase $a$ can be expressed as

$$
\left\{\begin{array}{l}
i_{a d m}=I_{a d m 0}+I_{m} \sin (\omega t-\varphi)+I_{a d m 2} \sin \left(2 \omega t-\varphi_{a d m 2}\right) \\
i_{a c m}=I_{a c m 0}+I_{a c m 1} \sin \left(\omega t-\varphi_{a c m 1}\right)+I_{a c m 2} \sin \left(2 \omega t-\varphi_{a c m 2}\right)
\end{array}\right.
$$

Combining the three sub-circuits, the arm voltages in leg $a$ can be expressed as

$$
\left\{\begin{array}{l}
v_{a p}=\widetilde{v}_{a 1}+\widetilde{v}_{a 2}+\bar{v}_{a} \\
v_{a n}=-\widetilde{v}_{a 1}+\widetilde{v}_{a 2}+\bar{v}_{a}
\end{array}\right.
$$

Rewriting (6), the instantaneous power in the upper and lower arms is

$$
\begin{aligned}
& p_{a p}=1 / 2 i_{a d m} \widetilde{v}_{a 1}+i_{a c m}\left(\widetilde{v}_{a 2}+\bar{v}_{a}\right)+1 / 2 i_{a d m}\left(\widetilde{v}_{a 2}+\bar{v}_{a}\right)+\widetilde{v}_{a 1} i_{a c m} \\
& p_{a n}=1 / 2 i_{a d m} \widetilde{v}_{a 1}+i_{a c m}\left(\widetilde{v}_{a 2}+\bar{v}_{a}\right)-1 / 2 i_{a d m}\left(\widetilde{v}_{a 2}+\bar{v}_{a}\right)-\widetilde{v}_{a 1} i_{a c m}
\end{aligned}
$$

Thus, the difference in energy stored between the upper and lower arms can be calculated as

$$
\begin{aligned}
e_{p n} & =\int\left(p_{a p}-p_{a n}\right) d t=\int\left(i_{a d m}\left(\widetilde{v}_{a 2}+\bar{v}_{a}\right)+2 \widetilde{v}_{a 1} i_{a c m}\right) d t \\
& =\int\left(\begin{array}{l}
I_{a d m 0} \bar{v}_{a}+2 I_{a c m 1} \sin \left(\omega t-\varphi_{a c m 1}\right) \widetilde{v}_{a 1} \\
+I_{a d m 2} \sin \left(2 \omega t-\varphi_{a d m 2}\right) \tilde{v}_{a 2} \\
+\left(I_{m} \sin (\omega t-\varphi)+I_{a d m 2} \sin \left(2 \omega t-\varphi_{a d m 2}\right)\right) \bar{v}_{a} \\
+\left(\begin{array}{l}
2 I_{a c m 0}+2 I_{a c m 1} \sin \left(\omega t-\varphi_{a c m l}\right) \\
+2 I_{a c m 2} \sin \left(2 \omega t-\varphi_{a c m 2}\right)
\end{array}\right) \widetilde{v}_{a 1} \\
+\left(\begin{array}{l}
I_{a d m 0}+I_{m} \sin (\omega t-\varphi) \\
+I_{a d m 2} \sin \left(2 \omega t-\varphi_{a d m 2}\right)
\end{array}\right) \widetilde{v}_{a 2}
\end{array}\right) d t
\end{aligned}
$$

The energy difference between the upper and lower arms is not zero in one complete period under the following two conditions:

- The differential-mode current (i.e. the output ac current) has a dc component $\left(I_{a d m 0} \neq 0\right)$ or a double frequency component $\left(I_{\text {adm2 }} \neq 0\right)$;

- The common-mode current includes a fundamental frequency component $\left(I_{a c m l} \neq 0\right)$.

From this analysis, it can be concluded that under asymmetrical impedance conditions, the following potential issues exist which could significantly affect MMC system operation:

- Unequal fundamental current distribution in the upper and lower arms, and the existence of fundamental current ripple on the de side;

- Existence of second order harmonic current on the output ac and de sides;

- Unequal energy in the upper and lower arms which results in SM capacitor voltage divergence between the upper and lower arms.

Therefore, to maintain stable operation of the MMC under asymmetrical conditions, three control targets need to be achieved: (1) ensure the ac fundamental frequency current is split equally between the upper and lower arms; (2) eliminate the second order harmonic current in the differential-mode (ac output) current; and (3) regulate the dc common-mode current to maintain balanced power between the upper and lower arms.

\section{IMPROVED CONTROL STRATEGY FOR ASYMMETRIC MMC}

According to the previous analysis, to ensure stable MMC operation under asymmetrical conditions, a control strategy including the following three controllers is proposed.

\section{A. Output ac (differential-mode) current controller}

The output ac (differential-mode) current controller is implemented similar to conventional VSC control based in the synchronous $d q$ frame [15]. The controller generates the required arm voltage for each phase, e.g. $v_{a p}^{*}$ and $v_{a n}^{*}$ for phase $a$. As this has been documented, no further details are given here.

\section{B. Common-mode current controller}

From previous analysis, elimination of the fundamental frequency common-mode current ensures equal distribution of the ac output current between the upper and lower arms. In addition, the second order harmonic current problem on the ac and dc sides can be resolved if such common-mode second order harmonic current is eliminated. Thus, the purpose of this controller is to eliminate both the fundamental (which is unique to asymmetrical conditions) and double-frequency current components in the common-mode current for each phase.

According to Fig. 2 and (4), the mathematical equation for the common-mode current is 


$$
\left\{\begin{array}{l}
\left(\left(R_{1}+R_{2}\right)+\left(L_{1}+L_{2}\right) \frac{d}{d t}\right) i_{a c m}=-\left(\widetilde{v}_{a p}+\widetilde{v}_{a n}\right) \\
\left(\left(R_{3}+R_{4}\right)+\left(L_{3}+L_{4}\right) \frac{d}{d t}\right) i_{b c m}=-\left(\widetilde{v}_{b p}+\widetilde{v}_{b n}\right) \\
\left(\left(R_{5}+R_{6}\right)+\left(L_{5}+L_{6}\right) \frac{d}{d t}\right) i_{c c m}=-\left(\widetilde{v}_{c p}+\widetilde{v}_{c n}\right)
\end{array}\right.
$$

Controlling the ac components in the arm voltages can regulate the common-mode current. To eliminate the main components in the common-mode current under an asymmetrical condition, a PR (proportional and resonant) controller with two resonant frequencies at $\omega_{0}$ and $2 \omega_{0}\left(\omega_{0}\right.$ is the fundamental frequency) is adopted in each leg, and the transfer function of the PR controller is [28]

$$
G(s)=K_{p}+\frac{2 K_{r 1} s}{s^{2}+\left(\omega_{0}\right)^{2}}+\frac{2 K_{r 2} s}{s^{2}+\left(2 \omega_{0}\right)^{2}}
$$

The control structure for phase $a$ is shown in Fig. 7, where the high pass filter (HPF) removes the dc component and extracts the ac components $\widetilde{i}_{\text {acm }}$ from the common-mode current $i_{a c m}$. The cut-off frequency of the HPF can be set at a low frequency, e.g. $2 \mathrm{~Hz}$, due to the fact that dynamic response is not the main concern for this controller. $\widetilde{i}_{a c m}^{*}$ is the reference value for the ac common-mode current which is set to zero to completely eliminate such components. The output from the PR controller, $\Delta v_{a c m}$, is added/subtracted to/from the normal upper and lower arm voltage references generated by the ac (differential mode) current controller.

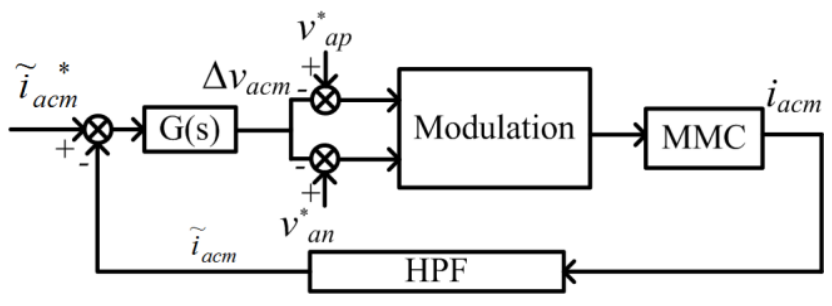

Fig.7 Control structure of the common-mode current for phase 'a'.

\section{Power balance controller}

With a common-mode current controller, the fundamental frequency and double frequency common-mode currents can be eliminated by adding $\Delta v_{a l}$ (for fundamental frequency) and $\Delta v_{a 2}$ (for double frequency) to the upper and lower arm voltages. Based on (9), the arm voltages in the proposed control strategy can be expressed as

$$
\left\{\begin{array}{l}
v_{a p}=\widetilde{v}_{a 1}+\Delta v_{a 1}+\tilde{v}_{a 2}+\Delta v_{a 2}+\bar{v}_{a p} \\
v_{a n}=-\widetilde{v}_{a 1}+\Delta v_{a 1}+\widetilde{v}_{a 2}+\Delta v_{a 2}+\bar{v}_{a n}
\end{array}\right.
$$

where $\Delta v_{a 1}$ and $\Delta v_{a 2}$ denote the additional voltage components generated by the common-mode current controller. $\bar{v}_{a p}$ and $\bar{v}_{a n}$ denote the dc offsets in the upper and lower arms respectively, which might be slightly different under asymmetrical conditions due to different arm resistances.
Rewriting (6), the instantaneous powers in the upper and lower arms are

$$
\left\{\begin{aligned}
p_{a p} & =\left(1 / 2 i_{a d m} \widetilde{v}_{a 1}+i_{a c m}\left(\Delta v_{a 1}+\widetilde{v}_{a 2}+\Delta v_{a 2}\right)\right) \\
& +\left(1 / 2 i_{a d m}\left(\Delta v_{a 1}+\widetilde{v}_{a 2}+\Delta v_{a 2}\right)+i_{a c m} \widetilde{v}_{a 1}\right) \\
& +\left(1 / 2 i_{a d m}+i_{a c m}\right) \bar{v}_{a p} \\
p_{a n} & =\left(1 / 2 i_{a d m} \widetilde{v}_{a 1}+i_{a c m}\left(\Delta v_{a 1}+\widetilde{v}_{a 2}+\Delta v_{a 2}\right)\right) \\
& -\left(1 / 2 i_{a d m}\left(\Delta v_{a 1}+\widetilde{v}_{a 2}+\Delta v_{a 2}\right)+i_{a c m} \widetilde{v}_{a 1}\right) \\
& +\left(-1 / 2 i_{a d m}+i_{a c m}\right) \bar{v}_{a n}
\end{aligned}\right.
$$

Thus, the energy storage difference between the upper and lower arms is

$$
e_{p n}=\int\left(\begin{array}{l}
i_{a d m} \Delta v_{a 1}+i_{a c m}\left(\bar{v}_{a p}-\bar{v}_{a n}\right)+2 i_{a c m} \widetilde{v}_{a 1} \\
+i_{a d m}\left(\tilde{v}_{a 2}+\Delta v_{a 2}\right)+1 / 2 i_{a d m}\left(\bar{v}_{a p}+\bar{v}_{a n}\right)
\end{array}\right) d t
$$

Eq. (17) indicates that energy difference $e_{p n}$ exists between the upper and lower arms in one complete period. Consequently, the total energy stored in the upper arm SM capacitors and lower arm capacitors can be different which results in the divergence of their voltages. Thus, to ensure SM capacitor voltages in the upper and lower arms balance, a power balance controller is needed in each phase.

Detailed analysis of (17) reveals that there exist two power balance methods. The second component in (17) indicates that the energy difference can be controlled by slightly changing $\left(\bar{v}_{a p}-\bar{v}_{a n}\right)$, i.e. the dc offsets of the upper and lower arm voltages, since the common-mode current $i_{a c m}$ now only contains the dc current. The schematic diagram using this control principle is shown in Fig. 8 for phase $a$. As shown, the difference between the total upper arm capacitor voltage (i.e. $\sum_{i=1}^{n} v_{p c i}$ where $v_{p c i}$ is the capacitor voltage of the $i$ th SM in the upper arm, and $n$ is the total number of SMs in an arm) and the lower arm total capacitor voltage (i.e. $\sum_{i=1}^{n} v_{n c i}$ where $v_{n c i}$ is the capacitor voltage of the $i^{\text {th }} \mathrm{SM}$ in the lower arm) is passed through a notch filter tuned at fundamental frequency $\omega_{0}$ to remove the fundamental frequency voltage ripple and extract the dc voltage unbalance $\Delta \bar{v}_{d c p n} . i_{a c m 0}$ is the dc component of the common-mode current and equals to $\mathrm{I}_{\mathrm{dc}} / 3$ under normal steady state condition. Their product is fed to a PI regulator whose reference input is zero to produce a small dc offset $\Delta v_{a}$ which is added to the upper and lower arm voltages with opposing polarities. According to (4), the added dc offset $\Delta v_{a}$ would have an effort on the output voltage, which is used to compensate the dc offset in the output voltage caused by the power difference between the upper arm and the lower arm under the asymmetric conditions. The response of the PI regulator can be tuned at a low frequency due to the slow dynamics of the voltage divergence. The limitation of this method is that the controller becomes ineffective when the dc component in the common-mode current is zero, i.e. when the 
converter is not transmitting real power. To solve this issue, a supplementary method derived from the third component in (17) is adopted. If a small common-mode current at the fundamental frequency, which has the same phase angle as the generated ac arm voltage, is added, the energy difference can be regulated. Fig. 9 shows the structure of the supplementary power balance method for phase $a$. As shown, $\omega t$ is the phase angle of the generated arm ac voltage and thus $m_{s a}$ is in phase with the fundamental frequency arm ac voltage with a magnitude of $1 . \Delta i_{a c m}$ is the injected common-mode current which is added to the normal common-mode current reference of zero to feed to the common-mode current controller shown in Fig. 7.

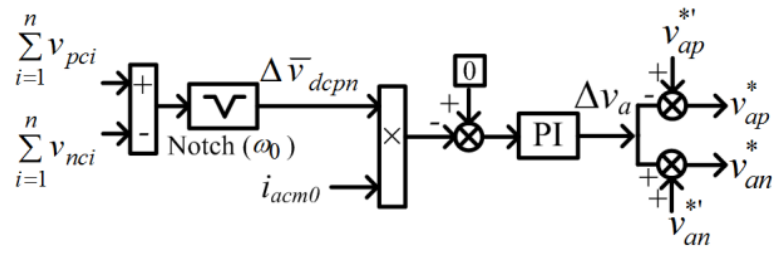

Fig.8 Structure of the power balance controller for phase $a$ using dc components.

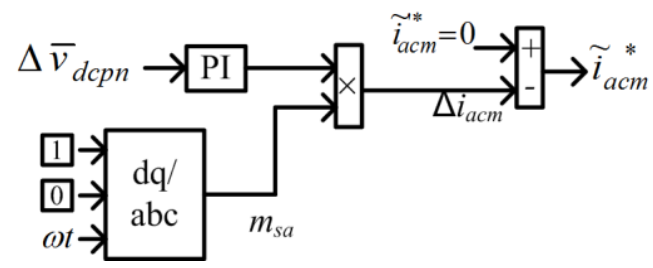

Fig.9 Structure of the power balance controller for phase $a$ using ac components.

The complete MMC control structure is shown in Fig. 10, where the superscript " "* denotes the reference values, and $v_{j p}{ }^{*}, v_{j n}{ }^{*}, i_{j c m}, \tilde{i}_{j c m}, i_{j c m 0}, \Delta i_{j c m}, \Delta v_{j c m}, \Delta v_{j}$ denote the required upper and lower arm voltages, common-mode current, the ac and dc components in common-mode current, the injected common-mode current derived from the power balance controller using ac components, the output voltage of PR controller in the common-mode current controller, and the output voltage of PI controller in the power balance controller using dc components in phase $a, b, c(j=a, b, c)$, respectively. The voltage reference is generated by three controllers, of which the differential-mode current controller regulates the active and reactive powers, the common-mode current controller suppresses the $50 \mathrm{~Hz}$ and $100 \mathrm{~Hz}$ circulating currents, and the power balance controller ensures the total voltages across the upper and the lower arm capacitors are equal.

The three additional voltage components generated by the proposed controller, i.e. the dc, fundamental and double frequency voltages, are added to the upper and lower arm voltages to compensate the unbalanced voltage drop across the asymmetrical arm reactors, the double frequency SM capacitor voltage ripple, and the capacitor voltage imbalance between the upper and lower arms. Consequently the ac voltage seen at the converter terminal will be free from any voltage unbalance and harmonics to ensure no $\mathrm{dc}$ and double frequency current in the ac output. Therefore, the injected components have no adverse effect on the MMC ac output.

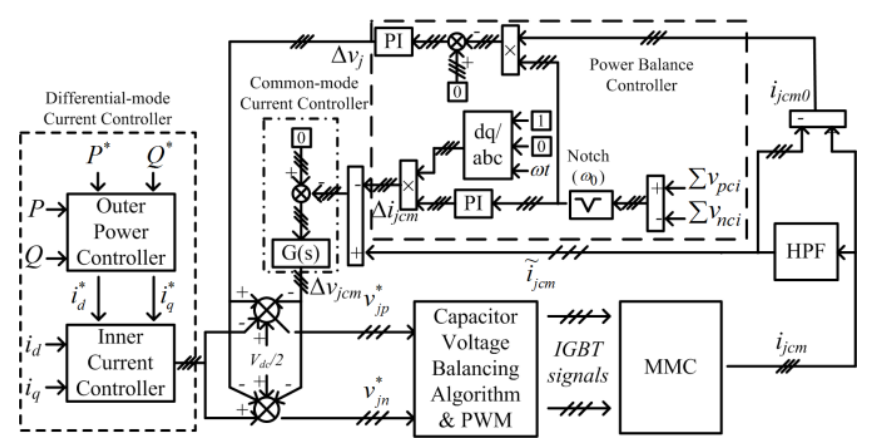

Fig. 10 Overall MMC control structure.

\section{Consideration of compensation limits for the proposed control strategy}

The proposed controller needs injected additional arm voltages and the maximum arm voltage that can be generated is limited by the operating point of the converter. Thus the relationship between the converter operating point (modulation index, dc voltage and ac current) and the unbalance ratio of the arm impedance is considered.

As the control scheme ensures the arm current only contains fundamental and $\mathrm{dc}$ components, only the fundamental voltage drop across the asymmetrical arm reactor is considered. According to the preceding analysis, in order to share the fundamental ac current equally, the voltages across the upper and lower arms including the voltage generated by the SMs and the voltage drop across the arm reactors must have identical amplitude but be phase shifted by $180^{\circ}$. The additional injected arm voltage generated by SMs in each arm therefore needs to compensate the voltage difference caused by the different upper and lower arm impedances. An extreme condition is considered here, in which one arm (e.g. upper arm) has the minimum arm impedance $\mathrm{L}_{\min }$ whereas the other arm in the same phase (e.g. lower arm) has the maximum arm impedance $\mathrm{L}_{\max }$. As illustrated in Fig. 3, the fundamental frequency quantities can be expressed as

$$
\begin{aligned}
& \widetilde{v}_{1}+\Delta \widetilde{v}_{1}+\frac{I_{a c}}{2} \sin (\omega t-\varphi) \times j \omega L_{\text {min }} \\
& =\widetilde{v}_{1}-\Delta \widetilde{v}_{1}+\frac{I_{a c}}{2} \sin (\omega t-\varphi) \times j \omega L_{\text {max }}
\end{aligned}
$$

where $\widetilde{v}_{1}$ is the normal voltage generated by the SMs, $\Delta \widetilde{v}_{1}$ is the additional injected arm voltage, and $I_{a c}$ is the ac current amplitude.

The unbalance ratio of $k$ and the additional injected arm voltage $\Delta \widetilde{v}_{1}$ are defined as

$$
k=\frac{L_{\max }-L_{\min }}{L}, \quad \Delta \widetilde{v}_{1}=\Delta m \times \frac{V_{d c}}{2} \sin \left(\omega t+\theta_{1}\right)
$$

where $\Delta m$ and $\theta_{l}$ are the modulation index and phase angle of the additional voltage component, and $\mathrm{L}$ is the average arm inductance.

Substituting (21) into (20) yields 


$$
\Delta m=\frac{\omega L \times I_{a c}}{2 V_{d c}} k, \quad \theta_{1}=\frac{\pi}{2}-\varphi
$$

Thus in order to perform the compensation, the converter must have the extra required modulation index margin $\Delta m$.

\section{Simulation RESUlts For A THREE-PHASE System}

To verify the proposed control strategy, a three-phase MMC was simulated using Matlab/Simulink. Fig. 11 shows the simulation system structure where the MMC employs the configuration in Fig. 1 with slightly different impedances in each arm. The main circuit parameters are listed in Table I and the maximum arm impedance unbalance ratio is approximately $10 \% . i_{a b c}$ denotes the ac current flowing out from the MMC as shown in Fig. 11.

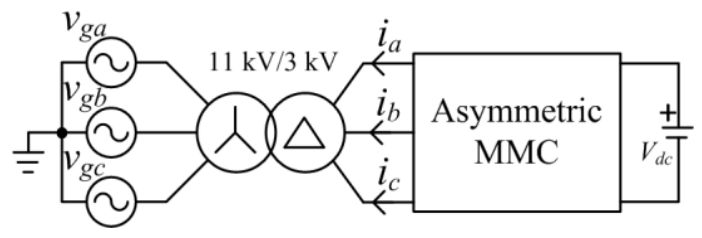

Fig. 11 Structure of the simulation system

TABLE I PARAMETERS FOR THE SIMULATED THREE-PHASE MMC SYSTEM

\begin{tabular}{c|c}
\hline Item & Values \\
\hline MMC rated power & $2.25 \mathrm{MW}$ \\
\hline DC voltage & $6 \mathrm{kV}$ \\
\hline Source voltage / frequency & $11 \mathrm{kV} / 50 \mathrm{~Hz}$ \\
\hline transformer ratio & $11 \mathrm{kV} / 3 \mathrm{kV}$ \\
\hline Rated impedance & $6.93 \Omega$ \\
\hline Transformer leakage impendence & $0.002+\mathrm{j} 0.2$ p.u. \\
\hline Number of SMs per arm & 4 \\
\hline DC voltage per SM & $1.5 \mathrm{kV}$ \\
\hline SM capacitor & $2200 \mu \mathrm{F}$ \\
\hline$R_{1}+j \omega L_{1}$ & $0.0036+\mathrm{j} 0.09$ p.u. \\
\hline$R_{2}+j \omega L_{2}$ & $0.0044+\mathrm{j} 0.11$ p.u. \\
\hline$R_{3}+j \omega L_{3}$ & $0.0041+\mathrm{j} 0.105$ p.u. \\
\hline$R_{4}+j \omega L_{4}$ & $0.0036+\mathrm{j} 0.09$ p.u. \\
\hline$R_{5}+j \omega L_{5}$ & $0.0044+\mathrm{j} 0.11$ p.u. \\
\hline$R_{6}+j \omega L_{6}$ & $0.0040+\mathrm{j} 0.10$ p.u. \\
\hline MMC carrier frequency & $4.0 \mathrm{kHz}$ \\
\hline
\end{tabular}

Figs. 12 (a) and (b) compare the steady-state waveforms under the conventional and proposed control strategies. Taking phase $a$ as an example, further analysis of the ac current $i_{a}$, fundamental arm current $i_{a p l}$ and $i_{a n l}$, and the common-mode current $i_{a c m}$ are carried out and the results for the conventional and proposed methods are compared in Table II. As can be observed from Fig. 12(a) and Table II, under conventional control the ac side current is unbalanced with dc offsets and second order $100 \mathrm{~Hz}$ harmonics. This confirms the previous analysis that under asymmetric arm impedances the common-mode currents (both dc and $100 \mathrm{~Hz}$ ) flow out to the ac side. The dc current shown in Fig. 12(a) also contains 50 $\mathrm{Hz}$ and $100 \mathrm{~Hz}$ ripples. The respective total capacitor voltages in the upper and lower arms which are calculated by adding all the SM capacitor voltages in the upper and lower arms, respectively, i.e., $\sum v_{p c i}$ and $\sum v_{n c i}$, also diverge. Again, these observations are in good agreement with the previous analysis. With the proposed control, Fig. 12 (b) and Table II clearly show that the ac side current is balanced with the dc and $100 \mathrm{~Hz}$ harmonics being largely eliminated. In addition, the $50 \mathrm{~Hz}$ and $100 \mathrm{~Hz}$ ripple in the dc current is also well suppressed and the total capacitor voltages in the upper and lower arms are rebalanced, as shown in Fig. 12(b). Equal current sharing for the upper and lower arms, i.e. $i_{a p l}$ and $i_{a n l}$ is largely achieved.

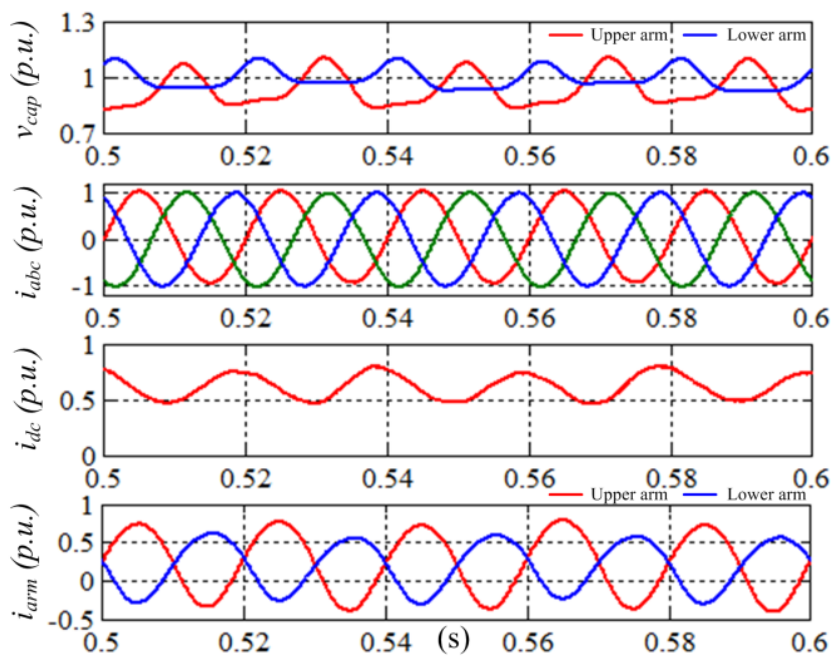

(a) With the conventional control strategy
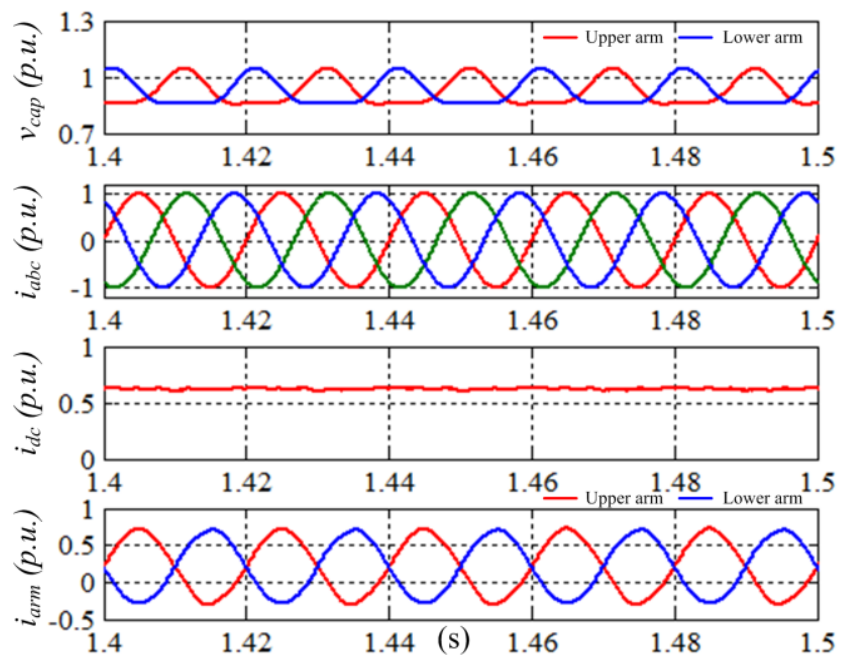

(b) With the proposed control strategy

Fig. 12 Simulation waveforms of steady-state operation for the asymmetrical MMC with $10 \%$ arm impedance mismatch; $v_{\text {cap }}$ : sum of the capacitor voltages in upper and lower arms; $i_{a b c}$ : output ac current; $i_{d c}$ : dc link current; $i_{a r m}$ : phase a upper and lower arm current.

TABLE II COMPARISON OF THE CONVENTIONAL AND PROPOSED METHODS

\begin{tabular}{|c|c|c|c|c|c|c|}
\hline \multicolumn{7}{|c|}{ ( $10 \%$ UNBALANCE RATIO) } \\
\hline & \multirow{2}{*}{$i_{a p 1}$} & \multirow{2}{*}{$i_{a n 1}$} & \multicolumn{2}{|c|}{$i_{a c m}$} & \multicolumn{2}{|c|}{$i_{a}$} \\
\hline & & & $50 \mathrm{~Hz}$ & $100 \mathrm{~Hz}$ & DC & $100 \mathrm{~Hz}$ \\
\hline Conventional & $56.3 \%$ & $43.7 \%$ & $7.2 \%$ & $4.1 \%$ & $2.8 \%$ & $1.4 \%$ \\
\hline Proposed & $50.2 \%$ & $49.8 \%$ & $0.4 \%$ & $0.4 \%$ & $0.2 \%$ & $0.1 \%$ \\
\hline
\end{tabular}

Fig. 13 presents the injected arm voltage components produced by the proposed controller. It can be observed that the output voltages of the PR controller $\Delta v_{c m}$ mainly include $50 \mathrm{~Hz}$ and $100 \mathrm{~Hz}$ components. The injected $50 \mathrm{~Hz}$ components compensate the voltage difference caused by the flowing of the $50 \mathrm{~Hz}$ arm current across the asymmetric upper and lower arm impedances. In order to completely eliminated the $100 \mathrm{~Hz}$ common-mode current, the injected $100 \mathrm{~Hz}$ 
voltages from the controller need to compensate the $100 \mathrm{~Hz}$ capacitor voltage ripple in the upper and lower arms. Therefore a substantial amount of $100 \mathrm{~Hz}$ voltage injection is required due to the significant capacitor voltage ripple. Increasing the SM capacitance can reduce the voltage ripple and the injected additional $100 \mathrm{~Hz}$ voltage component from the proposed controller. The small de voltages produced by the controller $\Delta v$ are injected to the upper and lower arms with oppose polarity to ensure the stored energy between the upper and the lower arm capacitors are balanced.
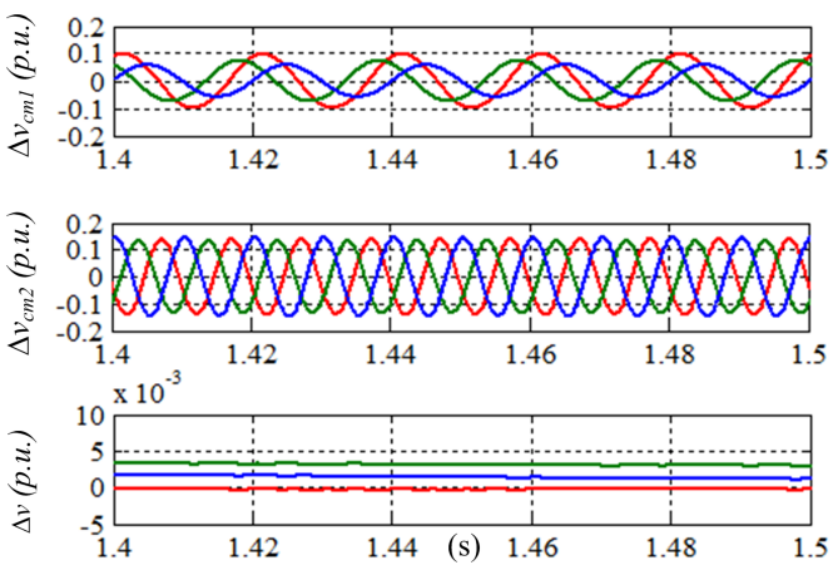

Fig. 13 Injected three-phase arm voltage components produced by the proposed controller; $\Delta v_{c m l}: 50 \mathrm{~Hz}$ components from the common-mode current controller; $\Delta v_{c m 2}: 100 \mathrm{~Hz}$ components from the common-mode current controller; $\Delta v$ : dc components from the power balance controller.
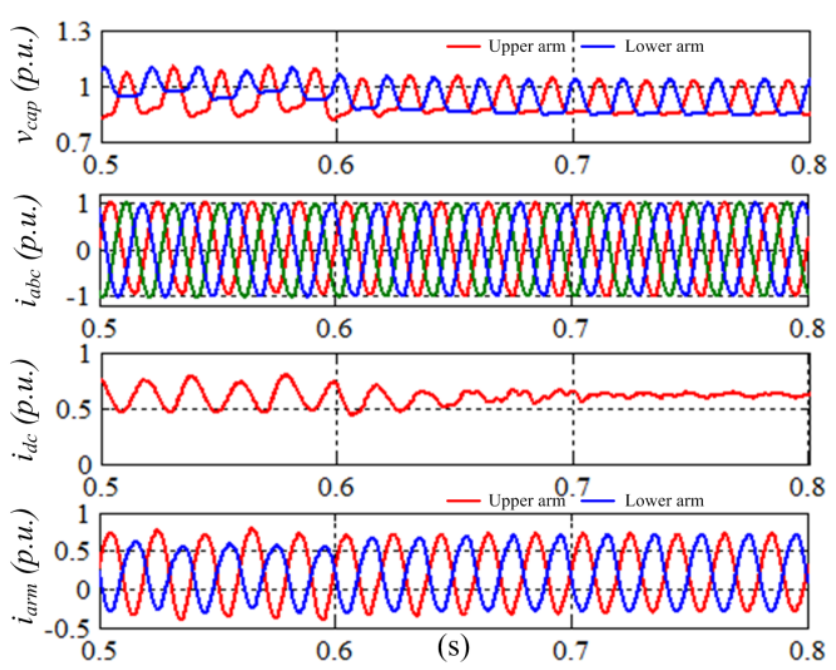

Fig. 14 Simulation waveforms of dynamic operation for $10 \%$ arm impedance mismatch, transferring from the conventional control strategy to the proposed control strategy at $0.6 \mathrm{~s}$.

Fig. 14 shows the transient performance where conventional control strategy is used prior to enabling the proposed control at $0.6 \mathrm{~s}$. As can be seen, once the proposed control strategy is enabled, the capacitor voltages in the upper and lower arms are quickly rebalanced and the output ac current, the dc current and the arm current are immediately improved. The simulation results clearly demonstrate the previous analysis and the effectiveness and validity of the proposed control strategy.
Further studies with a small arm impedance unbalance of approximately $2 \%$ were carried out and it was found that even with such a relatively small unbalance in arm impedance, it still has similar issues to the previous case shown in Figs. 1214. The main current harmonics are compared in Table III. As is shown, under such conditions, the common-mode current still contains $3.5 \% 50 \mathrm{~Hz}$ and $4.2 \% 100 \mathrm{~Hz}$ component. They are reduced to $0.08 \%$ and $0.3 \%$ respectively once the proposed control scheme is enabled indicating a significant improvement. It also can be observed that the dc and $100 \mathrm{~Hz}$ components in the ac output current are also significantly reduced.

TABLE III COMPARISON OF THE CONVENTIONAL AND PROPOSED METHODS

\begin{tabular}{|c|c|c|c|c|c|c|}
\hline \multirow{2}{*}{} & \multirow{2}{*}{$\boldsymbol{i}_{\boldsymbol{a p 1}}$} & \multirow{2}{*}{$\boldsymbol{i}_{\boldsymbol{a n 1}}$} & \multicolumn{2}{|c|}{$\boldsymbol{i}_{\boldsymbol{a c m}}$} & \multicolumn{2}{|c|}{$\boldsymbol{i}_{\boldsymbol{a}}$} \\
\cline { 4 - 7 } & & $\mathbf{5 0 H z}$ & $\mathbf{1 0 0 H z}$ & $\mathbf{D C}$ & $\mathbf{1 0 0 H z}$ \\
\hline Conventional & $51.9 \%$ & $48.1 \%$ & $3.5 \%$ & $4.2 \%$ & $0.7 \%$ & $0.5 \%$ \\
\hline Proposed & $50.0 \%$ & $50.0 \%$ & $0.08 \%$ & $0.3 \%$ & $0.03 \%$ & $0.02 \%$ \\
\hline
\end{tabular}

\section{EXPERIMENTAL AND SimULATION RESUltS FOR A Single- PHASE SYSTEM}

To test the presented analysis and the proposed control strategy, a prototype single-phase MMC schematically shown in Fig. 15 is developed. The control system is implemented using a TMS320F2812 DSP and the main circuit parameters are listed in Table IV. Two dc power sources are connected in series to form the dc neutral point. The unbalance ratio of the upper and lower arm inductances is approximately $6.4 \%$.

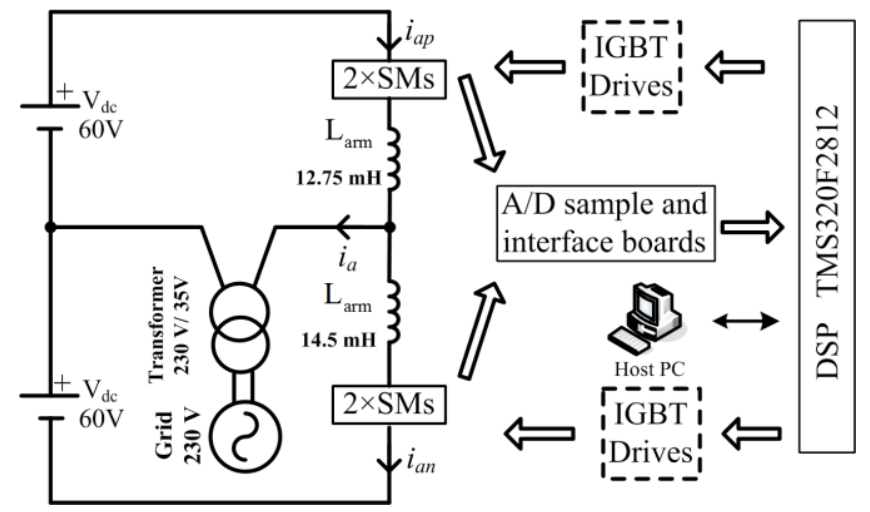

Fig. 15 Schematic of the asymmetrical MMC experimental system

TABLE IV

PARAMETERS OF THE EXPERIMENTAL MMC SYSTEM

\begin{tabular}{c|c}
\hline Item & Values \\
\hline MMC rated power & $150 \mathrm{~W}$ \\
\hline DC voltage & $120 \mathrm{~V}$ \\
\hline AC voltage (peak) & $50 \mathrm{~V}$ \\
\hline Number of SMs per arm & 2 \\
\hline DC voltage per SM & $60 \mathrm{~V}$ \\
\hline SM capacitor & $940 \mu \mathrm{F}$ \\
\hline Upper arm inductance & $12.75 \mathrm{mH}$ \\
\hline Lower arm inductance & $14.50 \mathrm{mH}$ \\
\hline Transformer leakage inductance & $16.8 \mathrm{mH}$ \\
\hline Transformer voltage ratio (rms.) & $230 \mathrm{~V} / 35 \mathrm{~V}$ \\
\hline MMC carrier frequency & $4.0 \mathrm{kHz}$ \\
\hline
\end{tabular}

Figs. 16 (a) and (b) show the steady-state operation of the MMC under the conventional and proposed control strategies, 
respectively. Further analysis of the ac current $i_{a}$, fundamental arm current $i_{a p l}$ and $i_{a n l}$, and the common-mode current $i_{a c m}$ are carried out and the results are compared in Table V for the conventional and proposed methods. As shown in Fig. 16(a) and Table $\mathrm{V}$, the upper arm current is larger than the lower arm current (due to the smaller arm inductance in the upper arm), and the common-mode current includes large $50 \mathrm{~Hz}$ and $100 \mathrm{~Hz}$ ripple components. The output ac current also contains $\mathrm{dc}$ and $100 \mathrm{~Hz}$ harmonics. Fig. 16(a) also shows that the difference between the average capacitor voltages in the upper and lower arms is around 10V. By contrast, Fig. 16(b) and Table $\mathrm{V}$ show that once the proposed control strategy is adopted the common-mode current becomes mainly dc with both the $50 \mathrm{~Hz}$ and $100 \mathrm{~Hz}$ components significantly reduced resulting in equal current sharing in the upper and lower arms. The dc and $100 \mathrm{~Hz}$ components in the output ac current are also reduced from $0.5 \%$ and $1.8 \%$ to $0.05 \%$ and $0.5 \%$ respectively. The capacitor voltages in the upper and lower arms are also balanced. During the measurement, the current probe used for measuring $i_{a n}$ shown in Fig.16 (b) contained a small offset but the ac magnitudes between $i_{a p}$ and $i_{a n}$ remain almost identical as evident from Table V.

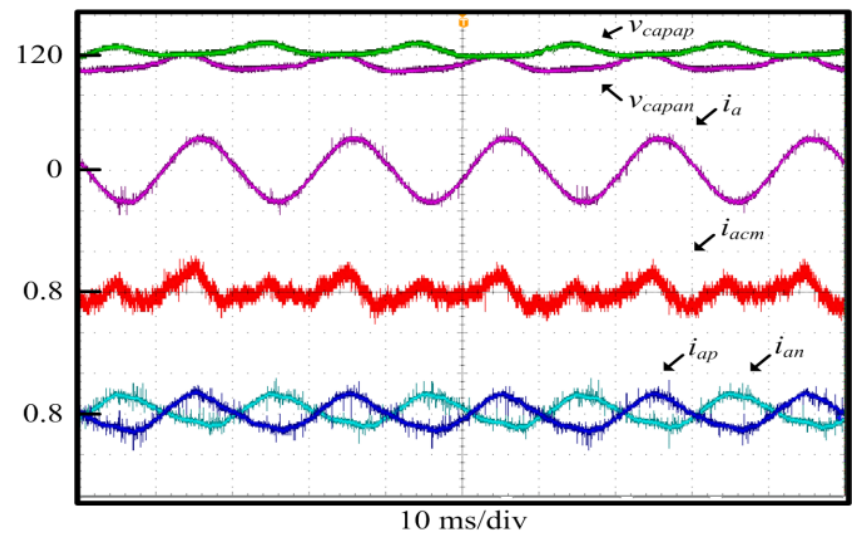

(a) With the conventional control strategy

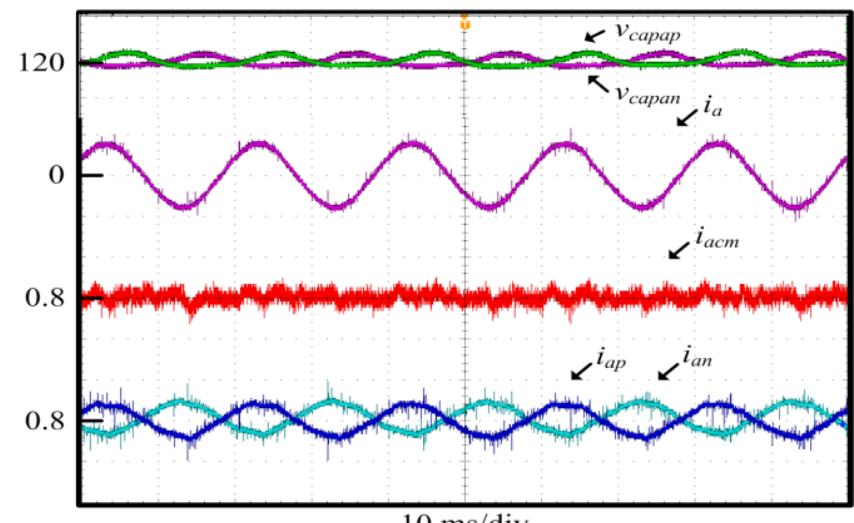

(b) With the proposed control strategy

$10 \mathrm{~ms} / \mathrm{div}$

Fig. 16 Steady-state operation as a grid-connected inverter; $v_{\text {capapa }}$ : sum of the upper arm capacitor voltage $(20 \mathrm{~V} / \mathrm{div}) ; v_{\text {capan }}$ : sum of the lower arm capacitor voltage $(20 \mathrm{~V} / \mathrm{div}) ; i_{a}$ : ac side current $(5 \mathrm{~A} / \mathrm{div}) ; i_{a c m}$ : common-mode current (2.5A/div); $i_{a p}$ : upper arm current $(5 \mathrm{~A} / \mathrm{div}) ; i_{a n}$ : lower arm current (5A/div).
TABLE V COMPARISON OF THE EXPERIMENTAL RESULTS FOR THE SINGLEPHASE SYSTEM

\begin{tabular}{|c|c|c|c|c|c|c|}
\hline & \multirow{2}{*}{$\boldsymbol{i}_{\boldsymbol{a p 1}}$} & \multirow{2}{*}{$\boldsymbol{i}_{\boldsymbol{a n 1}}$} & \multicolumn{2}{|c|}{$\boldsymbol{i}_{\boldsymbol{a c m}}$} & \multicolumn{2}{|c|}{$\boldsymbol{i}_{\boldsymbol{a}}$} \\
\cline { 4 - 7 } & $54.6 \%$ & $45.4 \%$ & $\mathbf{5 0 H z}$ & $\mathbf{1 0 0 H z}$ & $\mathrm{DC}$ & $\mathbf{1 0 0 H z}$ \\
\hline Conventional & $54.5 \%$ & $2.5 \%$ & $0.5 \%$ & $1.8 \%$ \\
\hline Proposed & $50.0 \%$ & $50.0 \%$ & $1.0 \%$ & $0.5 \%$ & $0.05 \%$ & $0.5 \%$ \\
\hline
\end{tabular}

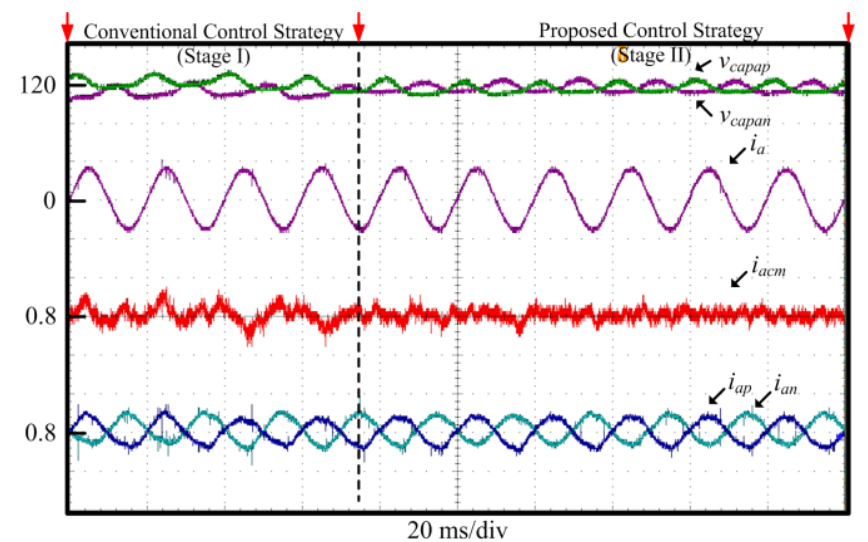

Fig. 17 Dynamic response when the system switches from conventional control to the proposed method.

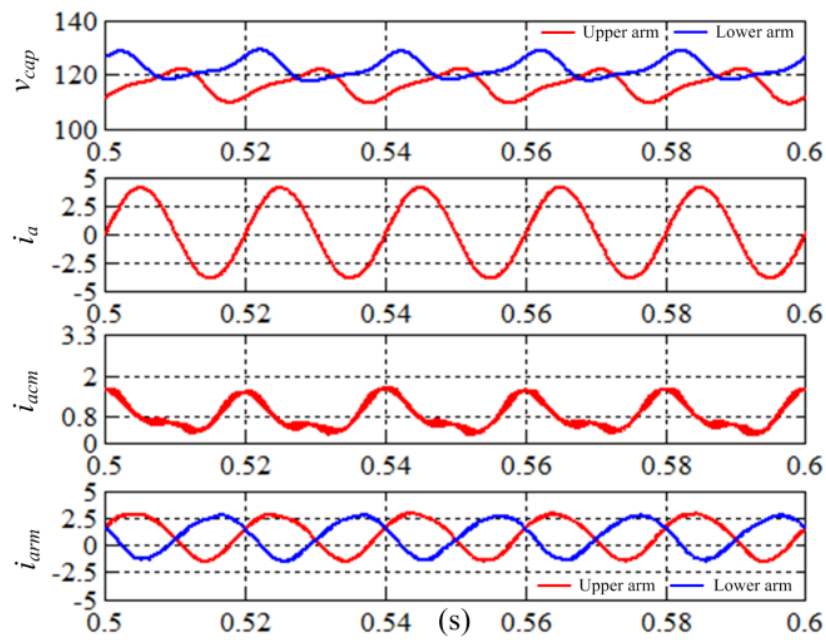

(a) With the conventional control strategy
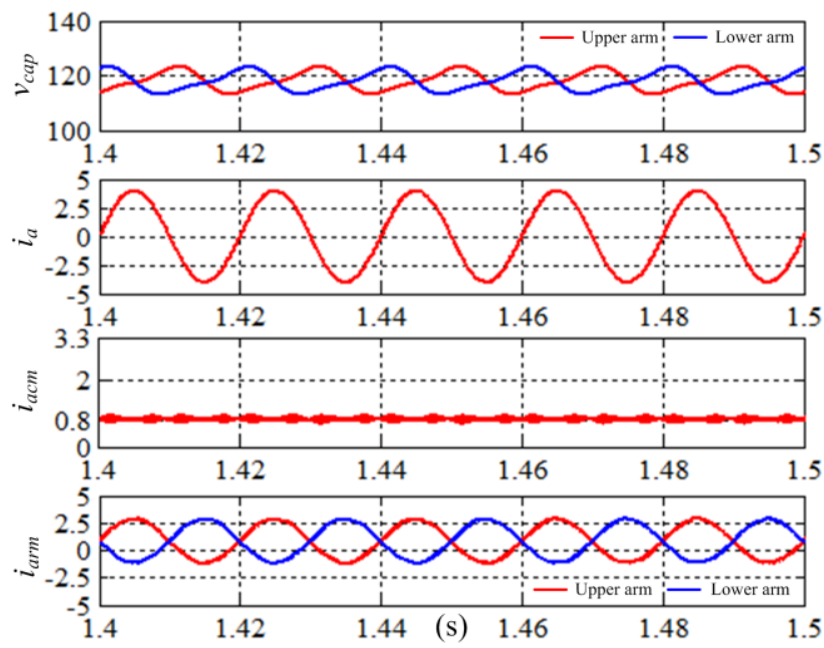

(b) With the proposed control strategy

Fig. 18 Simulation results of the steady-state operation for a single-phase asymmetrical MMC with the same parameters as the prototype; $v_{\text {cap }}$ : sum of the capacitor voltages in upper and lower arms; $i_{a}$ : ac side current; $i_{a c m}$ : common-mode current; $i_{\text {arm }}$ : upper and lower arm currents. 
Fig. 17 shows the MMC dynamic operation when the system switches from the conventional control strategy (Stage I) to the proposed control strategy (Stage II). As is shown, the proposed control strategy can quickly gain the control of capacitor voltage, and the ac and arm currents.

To further verify the proposed control strategy, additional simulation studies for a single-phase MMC with the same parameters as the prototype are carried out and the results are compared in Figs. 18 (a) and (b) and Table VI. It can be seen that similar trends can be observed as the experimental result shown in Fig. 16 and Table V. Under conventional control due to the complicated interactions among the diverged upper and lower capacitor voltages, asymmetric arm impedance and harmonic components in the arm and ac currents, the harmonic contents in the experimental and simulation results shown in Tables V and VI have some differences. However, both results are in good agreement with the theoretical analysis and clearly validate the effectively of the proposed method.

TABLE VI COMPARISON OF THE SIMULATED RESULTS FOR THE SINGLE-PHASE

\begin{tabular}{|c|c|c|c|c|c|c|}
\hline & \multirow{2}{*}{$\boldsymbol{i}_{\text {ap1 }}$} & \multirow{2}{*}{$\boldsymbol{i}_{\boldsymbol{a n 1}}$} & \multicolumn{2}{|c|}{$\boldsymbol{i}_{\boldsymbol{a c m}}$} & \multicolumn{2}{|c|}{$\boldsymbol{i}_{\boldsymbol{a}}$} \\
\cline { 4 - 7 } & & $\mathbf{5 0 H z}$ & $\mathbf{1 0 0 H z}$ & $\mathrm{DC}$ & $\mathbf{1 0 0 H z}$ \\
\hline Conventional & $55.0 \%$ & $45.0 \%$ & $8.5 \%$ & $5.0 \%$ & $1.02 \%$ & $1.77 \%$ \\
\hline Proposed & $50.0 \%$ & $50.0 \%$ & $0.43 \%$ & $0.14 \%$ & $0.02 \%$ & $0.03 \%$ \\
\hline
\end{tabular}

\section{CONCLUSIONS}

This paper proposes an MMC control strategy for asymmetrical arm impedance conditions. An equivalent circuit of the asymmetrical MMC is presented, and detail analysis of the impact of asymmetrical conditions on the differentialmode current, the common-mode current and capacitor voltages, was performed. Based on the analysis, three control targets were designed to improve asymmetrical MMC performance. To achieve these three control targets, an improved control strategy was proposed, involving three controllers: differential-mode current, common-mode current and power balance controllers. Detailed control system design was presented and the effectiveness of the proposed scheme in a three-phase MMC system and a single-phase MMC system was confirmed by the simulation studies and experimental results.

\section{REFERENCES}

[1] A. Lesnicar and R. Marquardt, "An innovative modular multilevel converter topology suitable for a wide power range," in Proc. IEEE Bologna Power Tech Conf., Jun. 2003, pp. 1-6.

[2] R. Zeng, L. Xu, L. Yao, and B. W. Williams, "Design and Operation of a Hybrid Modular Multilevel Converter", IEEE Trans. Power Electron., vol. 30, no. 3, pp. 1137-1146, March 2015.

[3] R. Marquardt, "Modular Multilevel Converter: An universal concept for HVDC-Networks and extended DC-Bus-applications," in Proc. Int. Power Electron. Conf., Jun. 2010, pp. 502-507.

[4] J. Mei, K. shen, B. Xiao, L.M. Tolbert and J. Zheng, "A new selective loop bias mapping phase disposition PWM with dynamic voltage balancing capability for modular multilevel converter," IEEE Trans. Ind. Electron., vol. 61, no. 2, pp. 798-807, Feb. 2014.

[5] M. Saeedifard and R. Iravani, "Dynamic performance of a modular multilevel back-to-back HVDC system," IEEE Trans. Power Del., vol. 25, no. 4, pp. 2903-2912, Oct. 2010.

[6] X. J. Shi, Z. Q. Wang, B. Liu, Y. Q. Liu, L. M. Tolbert, and F. Wang, "Characteristic investigation and control of a modular multilevel converter-based HVDC system under single-line-to-ground fault conditions," IEEE Trans. Power Electron., vol. 30, no. 1, pp. 408-421, Jan. 2015.

[7] J. Pou, S. Ceballos, G. Konstantinou, V. G. Agelidis, R. Picas and J. Zaragoza, "Circulating current injection methods based on instantaneous information for the modular multilevel converter," IEEE Trans. Ind. Electron., early access.

[8] F. Deng and Z. Chen, "Voltage-balancing method for modular multilevel converters switched at grid frequency," IEEE Trans. Ind. Electron., early access.

[9] E. Solas, G. Abad, J.A. Barrena, S. Aurtenetxea, A. Carcar and L. Zajac, "Modular multilevel converter with different submodule concepts - Part I: Capacitor voltage balancing method," IEEE Trans. Ind. Electron., vol. 60, no. 10, pp. 4525-4535, Oct. 2013.

[10] E. Solas, G. Abad, J.A. Barrena, S. Aurtenetxea, A. Carcar and L. Zajac, "Modular multilevel converter with different submodule concepts - Part II: Experimental validation and comparison for HVDC application," IEEE Trans. Ind. Electron., vol. 60, no. 10, pp. 4536-4545, Oct. 2013.

[11] K. Ilves, A. Antonopoulos, S. Norrga and H. Nee, "Steady-state analysis of interaction between harmonic components of arm and line quantities of modular multilevel converters," IEEE Trans. Power Electron., vol. 27, no. 1, pp. 57-68, Jan. 2012.

[12] Q. Song, W. H. Liu, Z. Q. Li, H. Rao, S. K. Xu and L. C. Li, "A steadystate analysis method for a modular multilevel converter," IEEE Trans. Power Electron., vol. 28, no. 8, pp. 3702-3713, Aug. 2013.

[13] L. Harnefors, A. Antonopoulos, S. Norrga, L. Angquist and H. P. Nee, "Dynamic analysis of modular multilevel converters," IEEE Trans. Ind. Electron., vol. 60, no. 7, pp. 2526-2537, Jan. 2013.

[14] M. Vasiladiotis, N. Cherix, and A. Rufer, "Accurate capacitor voltage ripple estimation and current control considerations for grid-connected modular multilevel converters," IEEE Trans. Power Electron., early access.

[15] Q. R. Tu, Z. Xu and L. Xu, "Reduced switching-frequency modulation and circulating current suppression for modular multilevel converters," IEEE Trans. Power Del., vol. 26, no. 3, pp. 2009-2017, Jul. 2011.

[16] Z. X. Li, P. Wang, Z. F. Chu, H. B. Zhu, Y. J. Luo and Y. H. Li, "An inner current suppressing method for modular multilevel converters," IEEE Trans. Power Electron., vol. 28, no. 11, pp. 4873-4879, Nov. 2013.

[17] M. Zhang, L. Huang, W.X. Yao and Z.Y. Lu, "Circulating harmonic current elimination of a CPS-PWM-Based modular multilevel converter with a plug-in repetitive controller," IEEE Trans. Power Electron., vol. 29, no. 4, pp. 2083-2097, Apr. 2014.

[18] L.Q. He, K. Zhang, J. Xiong and S.F. Fan, "Repetitive control scheme for harmonics suppression of circulating current in modular multilevel converter," IEEE Trans. Power Electron., early access.

[19] A. Antonopoulos, L. Angquist, and H.-P. Nee, "On dynamics and voltage control of the modular multilevel converter," in Proc. 13th Eur. Conf. Power Electron. Appl., 2009, pp. 1-10.

[20] L. Angquist, A. Antonopoulos, D. Siemaszko, K. Ilves, M. Vasiladiotis, and H. -P. Nee, "Open-loop control of modular multilevel converter using estimation of stored energy," IEEE Trans. Ind. Appl., vol. 47, no. 6, pp. 2516-2524, Nov. 2011.

[21] A. Antonopoulos, L. Angquist, L. Harnefors, K. Ilves, and H. -P. Nee, "Global asymptotic stability of modular multilevel converters," IEEE Trans. Ind. Electron., vol. 61, no. 2, pp. 603-612, Feb. 2014.

[22] S. Fan, K. Zhang, J. Xiong and Y. Xue, "An improved control system for modular multilevel converters with new modulation strategy and voltage balancing control," IEEE Trans. Power Electron., early access.

[23] G. Bergna, E. Berne, P. Egrot, P. Lefranc, A. Arzande, J. C. Vannier, and M. Molinas, "An energy-based controller for HVDC modular multilevel converter in decoupled double synchronous reference frame for voltage oscillation reduction," IEEE Trans. Ind. Electron., vol. 60, no. 6, pp. 2360-2371, Jun. 2013.

[24] Q. R. Tu, Z. Xu, Y. Chang and L. Guan, "Suppressing DC voltage ripples of MMC-HVDC under unbalanced grid conditions," IEEE Trans. Power Del., vol. 27, no. 3, pp. 1332-1338, Jul. 2012.

[25] M. Guan and Z. Xu, "Modeling and control of a modular multilevel converter-based HVDC system under unbalanced grid conditions," IEEE Trans. Power Electron., vol. 27, no. 12, pp. 4858-4867, Dec. 2012.

[26] J. W. Moon, C. S. Kim, J. W. Park, D. W. Kang, J. M. Kim, "Circulating current control in MMC under the unbalanced voltage," IEEE Trans. Power Del., vol. 28, no. 3, pp. 1952-1959, Jul. 2013. 


\section{IEEE TRANSACTIONS ON INDUSTRIAL ELECTRONICS}

[27] Y. B. Zhou, D. Z. Jiang, J. Guo, P. F. Hu and Y. Q. Liang, "Analysis and control of modular multilevel converters under unbalanced conditions," IEEE Trans. Power Del., vol. 28, no. 4, pp. 1986-1995, Oct. 2013.

[28] J. B. Hu, Y. K. He, L. Xu, and B. W. Williams, "Improved control of DFIG systems during network unbalance using PI-R current regulators," IEEE Trans. Ind. Electron., vol. 56, no. 2, pp. 439-451, Feb. 2009.

[29] J. B. Hu, and Y. K. He, "Modeling and control of grid-connected voltage-sourced converters under generalized unbalanced operation conditions," IEEE Trans. Energy Conv., vol. 23, no. 3, pp. 903-913, Sept. 2008.

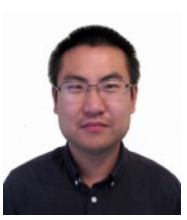

Rong Zeng (S'10) received the B.Sc. degree and M.Sc degree in electrical engineering from Hunan University, Changsha, China in 2008 and Zhejiang University, Hangzhou, China, in 2011, respectively.

Since 2012, he has been working toward the Ph.D. degree in the Department of Electronic \& Electrical Engineering, University of Strathclyde, Glasgow, UK. His research interest includes high power converters for HVDC application and grid integration of renewable energy systems.

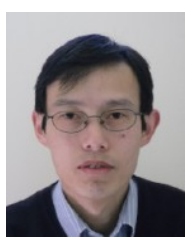

Lie Xu (SM'06) received the B.Sc. degree in Mechatronics from Zhejiang University, Hangzhou, China, in 1993, and the Ph.D. degree in Electrical Engineering from the University of Sheffield, Sheffield, UK, in 2000.

$\mathrm{He}$ is currently with the Department of Electronic \& Electrical Engineering, University of Strathclyde, Glasgow, UK. He previously worked in Queen's University of Belfast and ALSTOM T\&D, Stafford, UK. His research interests include power electronics, wind energy generation and grid integration, and application of power electronics to power systems.

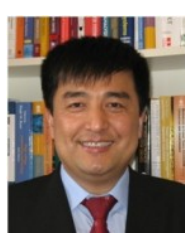

Liangzhong Yao (SM'12) received the M.Sc. degree in 1989 and $\mathrm{Ph} . \mathrm{D}$. degree in 1993 all in electrical power engineering from Tsinghua University, Beijing, China.

He joined the State Grid of China in 2011 and is now the Vice President of China Electric Power Research Institute (CEPRI). He was a post doctoral research associate at University of Manchester (former UMIST), UK from 1995 to 1999 , a senior power system analyst in the network consulting department at ABB UK Ltd from 1999 to 2004, and the department manager for network solutions, renewables \& smart grids technologies at ALSTOM Grid Research \& Technology Centre, Stafford, UK from 2004 to 2011. Dr Yao is a Chartered Engineer, a Fellow of the IET, and a member of the CIGRE. He is also a guest Professor at Shanghai Jiao Tong University, Shanghai, and Sichuan University, Chengdu, China.

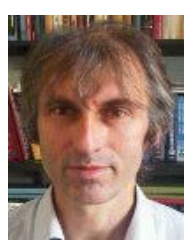

Stephen J. Finney obtained an M.Eng. degree in Electrical and Electronic Engineering from Loughborough University of Technology, UK in 1988 and Ph.D. degree in Electrical Engineering from Heriot-Watt University, Edinburgh, UK in 1994.

From 1994 to 2005 he was a member of academic staff at Heriot-Watt University. In 2005 he moved to the University of Strathclyde where he is currently Professor with the Institute of Energy and Environment, specialising in power electronic systems. His research interests include the power electronics for high power applications and the use of power electronics for power transmission and distribution. He has published extensively in IEEE and IEE journals. 